\title{
Recent history of fractional calculus
}

\author{
J. Tenreiro Machado, Virginia Kiryakova, Francesco Mainardi
}

\begin{abstract}
This survey intends to report some of the major documents and events in the area of frac-tional calculus that took place since 1974 up to the present date.
\end{abstract}

\author{
Keyword: \\ Fractional calculus
}

The fractional calculus (FC) may be considered an old and yet novel topic. It is an old topic because, starting from some speculations of G.W. Leibniz $(1695,1697)$ and L. Euler (1730), it has been developed progressively up to now. However, it may be considered a novel topic as well.

Only since the Seventies, the FC has been the object of specialized conferences and treatises. For the first conference the merit is due to B. Ross who, shortly after his Ph.D. dissertation on fractional calculus, organized the First Conference on Fractional Calculus and its Applications at the University of New Haven in June 1974, and edited its proceedings.

For the first monograph, the merit is ascribed to K.B. Oldham and J. Spanier, who, after a joint collaboration begun in 1968, published a book devoted to fractional calculus in 1974. This collaboration between a chemist (Oldham) and a mathematician (Spanier) in treating problems of mass and heat transfer in terms of the so-called semi-derivatives and semi-integrals, clearly manifested the origin of new era for FC based both on physical intuition and mathematical versatility. In 1987, the huge book of S. Samko, A. Kilbas and O. Marichev, referred to now as "encyclopedia" of FC, appeared first in Russian, and later with an English edition in 1993. Nowadays, the series of books, journals and texts devoted to fractional calculus and its applications includes several dozens of titles and this list is expected to grow up yet more, in the forthcoming years.

Fractional calculus, in allowing integrals and derivatives of any positive real order (the term "fractional" is kept only for historical reasons), can be considered as a branch of mathematical analysis which deals with integro-differential operators and equations where the integrals are of convolution type and exhibit (weakly singular) kernels of power-law type. It is strictly related to the theory of pseudo-differential operators. Related topics include special (higher transcendental) func- tions (including new classes closely associated with FC), integral transforms, (non-Gaussian, non-Markovian) stochastic pro- cesses, control theory, etc.

Fractional calculus can be considered as a "laboratory" for special functions and integral transforms. As an example, one can consider the special functions of mathematical physics as "generalized fractional integrals or derivatives" of three basic elementary functions, see e.g. V. Kiryakova book (1994), Ch. 4 and subsequent papers. Also, several generalized Laplace-type integral transforms can be seen as "transmutations", i.e. transmutation operators (which are fractional integrals) of the Laplace transform, see V. Kiryakova book (1994), Ch. 5. Special roles in the applications of fractional calculus are played by the transcendental functions of the Mittag-Leffler and Wright type, more generally by the Meijer G-functions and the Fox $H^{-}$ functions. On this respect, some of the books are: M.M. Dzherbashyan (1966), A.M. Mathai and R.K. Saxena (1973, 1978), H.M. Srivastava, K.C. Gupta, S.P. Goyal (1982), H.M. Srivastava and B.R.K. Kashyap (1982), A. Prudnikov, Yu. Brychkov and O. Marichev (1986, 1990), A. Kilbas and M. Saigo (2004), A. Kilbas, H.M. Srivastava and J. Trujillo (2006), A.M. Mathai and H. Haubold (2008), A.M. Mathai, R.K. Saxena and H. Haubold (2010), etc. 

Linear viscoelasticity is certainly the field of the most extensive applications of fractional calculus since its appearance, in view of its ability to model hereditary phenomena with long memory. For more details on this, see the books by M. Caputo (1969), A. Carpinteri and F. Mainardi (1997), I. Podlubny (1999), R. Hilfer (2000), B. West, M. Bologna and P. Grigolini (2003), A. Kilbas, H.M. Srivastava and J. Trujillo (2006) and the recent one by F. Mainardi (2010). See also the NASA Report by A. Freed, K. Diethelm, and Yu. Luchko (2002). But we could refer to other applications like finance, stochastic processes, and many branches of applied sciences and engineering, as proved by the increasing number of articles, congresses and treaties involving FC. In our opinion to cite review-survey papers on the applications of FC we have the risk to forget some because the list is long.

Signal processing, modeling and control is one of the areas that has been the object of more intensive publishing in the last decades. In fact, we can cite the pioneer work of A. Oustaloup (1991) that studied the application of fractional derivatives from the point of view of frequency response, and the important book by I. Podlubny (1999), covering a broad range of issues in the application of fractional calculus in automatic control. Nevertheless, going back, we verify that Oliver Heaviside introduced fractional derivatives in his book about electromagnetic theory (1920) and, later, A. Gemant (1936) applied fractional derivatives to problems in elasticity. It is nowadays recognized the advantage of using FC which is demonstrated by the increasing number of papers and special issues in journals.

In recent decades the field of fractional calculus has attracted interest of researchers in several areas including mathematics, physics, chemistry, engineering and even finance and social sciences.

But why is fractional calculus important?

Until recent times, fractional calculus was considered as a rather esoteric mathematical theory without applications, but in the last (few) decade (s) there has been an explosion of research activities on the application of fractional calculus to very diverse scientific fields ranging from the physics of diffusion and advection phenomena, to control systems to finance and economics. Indeed, at present, applications and/or activities related to fractional calculus have appeared in at least the following fields:

- Fractional control of engineering systems.

- Advancement of Calculus of Variations and Optimal Control to fractional dynamic systems.

- Analytical and numerical tools and techniques.

- Fundamental explorations of the mechanical, electrical, and thermal constitutive relations and other properties of various engineering materials such as viscoelastic polymers, foams, gels, and animal tissues, and their engineering and scientific applications.

- Fundamental understanding of wave and diffusion phenomenon, their measurements and verifications, including applications to plasma physics (such as diffusion in Tokamak). 
- Bioengineering and biomedical applications.

- Thermal modeling of engineering systems such as brakes and machine tools.

- Image and signal processing.

This survey intends to report some of the major documents and events in the area of fractional calculus that took place since 1974 up to the present date (April 2010) and is organized as follows. Section 1 presents some special issues in journals. Section 2 lists the books edited and the books with author (s) in this area. Section 3 reports list of conferences, special sessions in conferences, courses and thematic events that were devoted to FC. Sections 4-6 present related to FC specialized journals, numerical and software packages and mathematical keywords/mathematics subject classification (MSC2010), respectively. Finally, Section 7 includes some patent information.

\section{Preliminary note}

Clearly, lists such as those assembled in this paper, can never be complete, and, besides, there must be selective decisions. We do apologize for all omissions. Moreover, we do not give any judgment on the references: we limit ourselves to cite (possibly/hopefully) most of them.

\section{Special issues in journals}

Fractional Calculus and Applied Analysis, Special Issue "Proc. 3rd Intern. Workshop Transform Methods \& Special Functions, AUBG- Blagoevgrad' 1999” (with Special session on FC), vol. 2, No. 4-5, 1999, ISSNः1311-0454, Guest Editors: P. Rusev, I. Dimovski, V. Kiryakova [in English].

Physics Reports, Elsevier, “The Random Walk's Guide to Anomalous Diffusion: A Fractional Dynamics Approach”, vol. 339, No. 1, pp. 1-77, December 2000. Authors: Ralf Metzler, Joseph Klafter [in English].

Physics Reports, Elsevier, “Chaos, Fractional Kinetics, and Anomalous Transport”, vol. 371, No. 6, pp. 461-580, December 2002. Author: G.M. Zaslavsky [in English].

Chemical Physics, Elsevier, "Strange Kinetics", vol. 284, No. 1, pp. 1-541, November 2002, ISSN:0301-0104, Editors: R. Hilfer, R. Metzler, A. Blumen, J. Klafter [in English].

Nonlinear Dynamics, Kluwer, Special Issue "Fractional Order Systems", vol. 29, No. 1-4, pp. 1-385, July 2002, ISSN:0924090X, Guest Editor: J. A. Tenreiro Machado [in English].

Signal Processing, Elsevier, Special Issue "Fractional Signal Processing and Applications", vol. 83, No. 11, pp. 2285-2480, November 2003, ISSN:0165-1684, Guest Editors: Manuel D. Ortigueira, J.A. Tenreiro Machado [in English].

Mathematica Balkanica (J. Math. Soc. S-E Europe), Special Issue "Proc. 4th Intern. Symp. Transform Methods \& Special Functions, Borovets'2003" (with Special session on FC), vol. 18, No. 3-4, 2004, ISSN:0205-3217, Guest Editors: P. Rusev, I. Dimovski, V. Kiryakova [in English].

Nonlinear Dynamics, Kluwer, Special Issue "Fractional Derivatives and Their Applications", vol. 38, No. 1-4, pp. 1-489, December 2004, ISBN 0924-090X, Guest Editors: Om Prakash Agrawal, J.A. Tenreiro Machado, Jocelyn Sabatier [in English]. Signal Processing, Elsevier, Special Issue "Fractional Calculus Applications in Signals and Systems", vol. 86, No. 10, pp. 2503-3094, October 2006, ISSN:0165-1684, Guest Editors: Manuel D. Ortigueira, J.A. Tenreiro Machado [in English].

Journal of Computational and Applied Mathematics, Elsevier, Special issue "Evolutionary Problems", vol. 205, No. 2, pp. 667-1022, August 2007, ISSN:0377-0427, Edited by: C.T.H. Baker, K. Burrage, N.J. Ford [in English].

Journal of Vibration and Control, Sage Pub, Special Issue "Mathematical Methods in Engineering", vol. 13, No. 9-10, pp. 1207-1516, September 2007, ISSN:1077-5463, Guest Editors: K. Tas, J.A. Tenreiro Machado, Dumitru Baleanu [in English].

Journal of Advanced Computational Intelligence and Intelligent Informatics, Fuji Technology Press, Special issue on IEEEICCC 2006, Fuji Technology Press, vol. 11, No. 9, pp. 1061-1172, November 2007, ISSN: 1343-0130, Guest Editors: Béla Patkái, J.A. Tenreiro Machado, Imre J. Rudas [in English].

Journal of Vibration and Control, Sage Pub, Special Issue "Fractional Differentiation and its Applications", vol. 14, pp. 1253-1672, September 2008, ISSN:1077-5463, Guest Editors: J.A. Tenreiro Machado, Ramiro Barbosa, ISSN:1077-5463 [in English].

ASME Journal of Computational and Nonlinear Dynamics, Special Issue "Discontinuous and Fractional Dynamical Sys" tems", vol. 3, No. 2, p. 125, April 2008, Guest Editors: J.A. Tenreiro Machado, Albert Luo [in English].

Journal Européen des Systèmes Automatisés, Hermes, Special Issue on "Fractional order systems: Applications in Modelling, Identification and Control”, vol. 42, No. 6-8, pp. 625-1051, August-October 2008, ISSN:1269-6935, Guest Editors: Jocelyn Sabatier, Pierre Melchior, J.A. Tenreiro Machado, Blas Vinagre [in English].

Physica Scripta, "Fractional Differentiation and its Applications", 2009, Editors: George Zaslavsky, Dumitru Baleanu, J.A. Tenreiro Machado, T136, ISSN:0031-8949 [in English].

Journal of Computational and Applied Mathematics, Elsevier, Special issue "Innovative Methods for Solving Evolutionary Problems", vol. 228, No. 2, pp. 503-602, June 2009, ISSN:0377-0427, Edited by: B. Paternoster, E. Russo, A. Vecchio [in English]. 
Computers and Mathematics with Applications, Elsevier, Special Issue "Advances in Fractional Differential Equations", vol. 59, No. 3, pp. 1047-1376, February 2010, Editor: Yong Zhou, ISSN:0898-1221 [in English].

Computers and Mathematics with Applications, Elsevier, Special Issue "Fractional Differentiation and its Applications", vol. 59, No. 5, pp. 1585-1896, March 2010, Editors: Wen Chen, Dumitru Baleanu, J.A. Tenreiro Machado, ISSN:0898-1221 [in English].

Signal Processing, Elsevier, Special Issue “Advances in Fractional Signals and Systems”, 2010 (in progress), Editors: M.D. Ortigueira, B. Vinagre, J.A. Tenreiro Machado, J.J. Trujillo, ISSN:0165-1684 [in English].

2. Books

\subsection{Books edited}

B. Ross (Editor), Fractional Calculus and Its Applications: Proceedings of the International Conference held at the University of New Haven, June 1974 (Lecture Notes in Mathematics 457), 1975, 392 pages, ISBN-10:354007161X, ISBN-13:9783540071617 [in English].

A.C. McBride, G.F. Roach (Editors), Fractional Calculus (Proc. of International Conference held in Ross Priory - University of Strathclyde, Scotland, August 1984), Research Notes in Mathematics No. 138, Pitman, 1985, 214 pages, ISBN:0-273-08753-3 [in English].

H.M. Srivastava, Owa Shigeyoshi (Editors), Univalent Functions, Fractional Calculus and Their Applications, Ellis Horwood Ltd, 1990, 218 pages, ISBN-10:0139503870, ISBN-13:978-0139503870 [in English].

R.N. Kalia (Editor), Recent Advances in Fractional Calculus (Global Research Notes in Mathematics Ser.), Global Pub Co, 1993, 308 pages, ISBN-10:0963815504, ISBN-13:978-0963815507 [in English].

P. Rusev, I. Dimovski, V. Kiryakova (Editors), Transform Methods \& Special Functions, Sofia'1994 (Proc. 1st Intern. Workshop, with Special session on FC), SCTP - Singapore, 1995, 380 pages [in English].

Alberto Carpinteri, Francesco Mainardi (Editors), Fractals and Fractional Calculus in Continuum Mechanics (CISM International Centre for Mechanical Sciences), Springer, 1997, 300 pages, ISBN-10:321182913X, ISBN-13:978-3211829134 [in English].

P. Rusev, I. Dimovski, V. Kiryakova (Editors), Transform Methods \& Special Functions, Varna '96 (Proc. 2nd International Workshop, with special session on FC and "Open Problems in FC" Round Table), IMI - BAS, Sofia, 1998 , 612 pages, ISBN:9548986-05-1 [in English].

Rudolf Hilfer (Editor), Applications of Fractional Calculus in Physics, World Scientific Publishing Company, 2000,463 pages, ISBN-10:9810234570, ISBN-13:978-9810234577 [in English].

Alain Le Méhauté, J.A. Tenreiro Machado, Jean Claude Trigeassou, Jocelyn Sabatier (Editors), Fractional Differentiation and its Applications, Ubooks, Germany, 2005, 780 pages, ISBN:3-86608-026-3 [in English].

Wilfried Elmenreich, J.A. Tenreiro Machado, Imre J. Rudas (Editors), Intelligent Systems at the Service of Mankind - vol. 2, Ubooks, Germany, 2005, 478 pages, ISBN:3-86608-052-2 [in English].

Kenan Tas, J.A. Tenreiro Machado, Dumitru Baleanu (Editors), Mathematical Methods in Engineering, Springer, 2007, 470 pages, ISBN-10:140205677X, ISBN-13:978-1402056772 [in English].

Jocelyn Sabatier, Om Prakash Agrawal, J.A. Tenreiro Machado (Editors), Advances in Fractional Calculus: Theoretical Developments and Applications in Physics and Engineering, Springer, 2007, 552 pages, ISBN-10:1402060416, ISBN- 13:9781402060410 [in English].

Rainer Klages, Günter Radons, Igor M. Sokolov (Editors), Anomalous Transport: Foundations and Applications, Wiley-VCH, 2008, 608 pages, ISBN-10:3527407227, ISBN-13:978-3527407224 [in English].

Hans J. Haubold, A.M. Mathai (Editors), Proc. of the Third UN/ESA/NASA Workshop on the International Heliophysical Year 2007 and Basic Space Science: National Astronomical Observatory of Japan (Astrophysics and Space Science Proceedings), Springer, 2009, 190 pages, ISBN-10:3642033237, ISBN-13:978-3642033230 [in English].

Dumitru Baleanu, J.A. Tenreiro Machado, Ziya B. Guvenc (Editors), New Trends in Nanotechnology and Fractional Calculus Applications, Springer, 2010, 531 pages, ISBN-10:9048132924, ISBN-13:978-9048132928 [in English].

Albert C.J. Luo, Valentin S. Afraimovich (Editors), Long-range Interaction, Stochasticity and Fractional Dynamics - Dedication to George M. Zaslavsky (1935-2008), co-published by Higher Education Press and Springer, To appear in 2010 [in English].

J. Klafter, S.C Lim, R. Metzler (Editors), Fractional Dynamics in Physics, World Scientific, To appear in $2010-2011$ [in English].

\subsection{Books with author}

M.M. Dzherbashyan (Dzherbashian, Džrbashjan), Integral Transforms and Representations of Functions in Complex Domain, Nauka, Moscow, 1966, 672 pages, UDK 517.53 (MR, MathSciNet: MR209472) [In Russian].

Michele Caputo, Elasticitá e Dissipazione, Zanichelli, Bologna, 1969 [in Italian]. 
A.M. Mathai, R.K. Saxena, Generalized Hypergeometric Functions with Applications in Statistics and Physical Sciences, Lecture Notes in Mathematics, Springer, 1973, 324 pages, ISBN-10:3540064826, ISBN-13:978-3540064824 [in English].

Keith B. Oldham, Jerome Spanier, The Fractional Calculus: Theory and Application of Differentiation and Integration to Arbitrary Order, Dover Books on Mathematics, 1974, 234 pages, ISBN:978-0486450018 [in English].

Yu. N. Rabotnov, Elements of Hereditary Solids Mechanics, Nauka, Moscow, 1977 [In Russian]; Transl. from Russian by M. Konyaeva, Mir Publishers, Moscow, 1980, 387 pages, LCCN:80515676 [In English].

A.M. Mathai, R.K. Saxena, The $H$-function with Applications in Statistics and Other Disciplines, Wiley Eastern Ltd, New Delhi, 1978, 192 pages, Hc ISBN:0 85226559 X [In English].

Ian N. Sneddon, The Use of Operators of Fractional Integration in Applied Mathematics, Polish Acad. Sci., Appl. Math. Series, Warszawa-Poznan, 1979, 42 pages, ISBN-10:83-01-00188-7, ISBN-13:978-8301001889 [in English].

Adam C. McBride, Fractional Calculus and Integral Transforms of Generalized Functions, Pitman Press, San Francisco, 1979, 179 pages, ISBN-10:0273084151, ISBN-13:978-0273084150 [in English].

H.M. Srivastava, K.C. Gupta, S.P. Goyal, The H-Functions of One and Two Variables with Applications, South Asian Publishers, New Delhi and Madras, 1982, 306 pages [In English].

H.M. Srivastava, B.R.K. Kashyap, Special Functions in Queuing Theory and Related Stochastic Processes, Academic Press, Inc., New York, 1982, 308 pages, ISBN:0-1266-0650-1 [In English].

Alain Oustaloup, Systèmes asservis linéaires d'ordre fractionnaire: Théorie et pratique (Serie Automatique), Masson, 1983, 296 pages, ISBN-10:2225789703, ISBN-13:978-2225789700.

Katsuyuki Nishimoto, Fractional Calculus, vol. 1, Descartes Press, Koriyama, Japan, 1984, 194 pages [in English].

A.P. Prudnikov, Yu.A. Brychkov, O.I. Marichev, Integrals and Series, vol. 3: More Special Functions, Nauka, Moscow, 1986, 800 pages, UDK 519.6 [In Russian] (Rev. Ed. by Gordon and Breach Science Publishers, 1990, 1998, etc., ISBN:2-88124-682-6 [In English]).

Stefan G. Samko, Anatoly A. Kilbas, Oleg I. Marichev, Integrals and Derivatives of Fractional Order and Some of Their Applications, Nauka i Tekhnika, Minsk, 1987, 688 pages, with 1421 Refs., UDK 517.3 [In Russian].

Katsuyuki Nishimoto, Fractional Calculus, vol. 2, Descartes Press, Koriyama, Japan, 189 pages, 1987 [in English].

Katsuyuki Nishimoto, Fractional Calculus, vol. 3, Descartes Press, Koriyama, Japan, 1989 [in English].

Katsuyuki Nishimoto, Fractional Calculus, vol. 4, Descartes Press, Koriyama, Japan, 158 pages, 1991 [in English].

Katsuyuki Nishimoto, An Essence of Nishimoto's Fractional Calculus (Calculus of the 21st Century), Integrals and Differentiations of Arbitrary Order, Descartes Press, Koriyama, Japan, 208 pages, 1991 [in English].

Alain Oustaloup, La Commande CRONE: Commande Robuste d'Ordre Non Entier, Hermes, 1991, 495 pages, ISBN:2-86601289-5 [in French].

Rudolf Gorenflo, Sergio Vessella, Abel Integral Equations: Analysis and Applications, [Lecture Notes in Mathematics, vol. 1461], Springer, 1991, 215 pages, ISBN-10:354053668X, ISBN-13:978-3540536680 [in English].

M. Caputo, Lectures on Seismology and Rheological Tectonics, Lecture Notes, Universitá La Sapienza, Dipartimento di Fisica, Roma, 1992, 319 pages, Enlarged and revised edition based on the first edition [in English].

H.M. Srivastava, R.G. Buschman, Theory and Applications of Convolution Integral Equations, Kluwer Series on Mathematics and Its Applications, vol. 79, Kluwer Academic Publishers, 1992, 240 pages, ISBN:0792318919 [in English].

Stefan G. Samko, Anatoly A. Kilbas, Oleg I. Marichev, Fractional Integrals and Derivatives: Theory and Applications, Gordon and Breach Science Publishers, 1993, 1006 pages, ISBN-10:2881248640, ISBN-13:978-2881248641 [in English].

Kenneth S. Miller and Bertram Ross, An Introduction to the Fractional Calculus and Fractional Differential Equations, John Wiley and Sons, 1993, 384 pages, ISBN-10:0471588849, ISBN-13:978-0471588849 [in English].

Semen B. Yakubovich, Yury F. Luchko, The Hypergeometric Approach to Integral Transforms and Convolutions, Ser. Mathematics and Its Applications, vol. 287, Kluwer Academic Publishers, Dordrecht/Boston/London, 1994, 324 pages, ISBN:07923-2856-6.

Virginia S. Kiryakova, Generalized Fractional Calculus and Applications, Pitman Research Notes in Mathematics, vol. 301, Longman Sci. Tech. \& J. Wiley, 1994, 388 pages, ISBN-0:0582219779, ISBN-13:978-0582219779, ISBN:0-470-23376-1 [in English].

Alain Oustaloup, La Dérivation Non Entière. Théorie, Synthèse et Applications, Hermès Science, 1995 , 508 pages, ISBN:978-2866014568 [in French].

Katsuyuki Nishimoto, Fractional Calculus, vol. 5, Descartes Press, Koriyama, Japan, 1996 [in English].

Boris Rubin, Fractional Integrals and Potentials, Pitman Monographs and Surveys in Pure and Applied Mathematics, vol. 82, Longman Sci. Techn./CRC Press, 1996, 424 pages, ISBN-10:0582253411, ISBN-13:978-0582253414 [in English].

Alain Le Méhauté, Raoul R. Nigmatullin, Laurent Nivanen, Flèches du temps et géométrie fractale, Hermes, 2 édition, 1998, 348 pages, ISBN:978-286601-682-3 [in French].

Igor Podlubny, Fractional Differential Equations, Volume 198: An Introduction to Fractional Derivatives, Fractional Differential Equations, to Methods of Their Solution (Mathematics in Science and Engineering), Academic Press, 1999,340 pages, ISBN-10:0125588402, ISBN-13:978-0125588409 [in English].

A. Oustaloup, B. Mathieu, La commande CRONE: du scalaire au multivariable, Hermes Ed., Paris, 1999,315 pages, ISBN:27462-0043-0, ISSN:0989-3571 [in French]. 
Vladimir V. Uchaikin, Vladimir M. Zolotarev, Chance and Stability. Stable Distributions and their Applications, VSP, Utrecht 1999. [Series "Modern Probability and Statistics", No. 3, 596 pages, ISBN-10:9067643017, ISBN-13:978-9067643016 [in English].

BruceJ. West, Physiology, Promiscuity, and Prophecy at the Millennium: ATale of Tails, (Studies of Nonlinear Phenomena in Life Sciences, vol. 8), World Scientific Publishing Company, 1999, 443 pages, Language: English, ISBN-10:9810238355, ISBN-13:978-9810238353 [in English].

Paolo Arena, R. Caponetto, M. Porto, L. Fortuna, Nonlinear Noninteger Order Systems: Theory and Applications, 212 pages, World Scientific Publishing Company, 2001, ISBN-10:9810244010, ISBN-13:978-9810244019 [in English].

Svante Westerlund, Dead Matter Has Memory!, Causal Consulting, Kalmar, Sweden, 2002, 219 pages, ISBNः91-631-23320 [in English].

I. Petras, I. Podlubny, P. O'Leary, L. Dorcak, B. Vinagre: Analogue Realization of Fractional Order Controllers. FBERG, Technical University of Kosice, Kosice, 2002, 84 pages, ISBN:8070996277 [in English].

A. Freed, K. Diethelm, Yu. Luchko: Fractional Order Viscoelasticity (FOV): Constitutive Development Using the Fractional Calculus: First Annual Report, NASA/TM 2002-211914, NASA's Glenn Research Center, Brook Rark, Ohio, December 2002, 121 pages [in English].

Niels Jacob, Pseudo-Differential Operators and Markov Processes: Fourier Analysis and Semigroups (vol. 1), World Scientific Publishing Company, 2002, 440 pages, ISBN-10:1860942938, ISBN-13: 978-1860942938 [in English].

Niels Jacob, Pseudo-Differential Operators \& Markov Processes: Generators and Their Potential Theory (vol. 2), World Scientific Publishing Company, 2nd edition, 476 pages, 2002, ISBN-10:1860943241, ISBN-13:978-1860943249 [in English].

Bruce West, Mauro Bologna, Paolo Grigolini, Physics of Fractal Operators, Springer, 2003, 368 pages, ISBN10:0387955542, ISBN-13:978-0387955544 [in English].

Blanca Bonilla Paz, Juan José Trujillo Jacinto del Castillo, Anatoly A. Kilbas, Calculo Fraccionario y Ecuaciones Diferenciales Fraccionarias, Universidad Nacional de Educación a Distancia, UNED, Ediciones, Madrid, 2003, 206 pages, ISBN:8436248937 [in Spanish].

Adam M. Nakhushev, Fractional Calculus and its Applications, Fizmatlit, Moscow, 2003, 272 pages, ISBN:5-9221-0440-3 [in Russian].

Anatoly A. Kilbas, Megumi Saigo, H-Transforms: Theory and Applications, [Series on Analytic Methods and Special Functions, vol. 9.], CRC Press, 2004, 408 pages, ISBN-10:0415299160, ISBN-13:978-0415299169 [in English].

Niels Jacob, Pseudo-Differential Operators \& Markov Processes: Markov Processes and Applications (vol. 3), Imperial College Press, 2005, 474 pages, ISBN-10:1860945686, ISBN-13:978-1860945687 [in English].

A.V. Pskhu, Partial Differential Equations of Fractional Order, Nauka, Moscow, 2005, ISBN: 5-02-033721-8 [in Russian].

Richard L. Magin, Fractional Calculus in Bioengineering, Begell House Publishers, 2006, 684 pages, ISBN-10:1567002153, ISBN-13:978-1567002157 [in English].

A.A. Kilbas, H.M. Srivastava, J.J. Trujillo, Theory and Applications of Fractional Differential Equations, vol. 204 (North-Holland Mathematics Studies), Elsevier, 2006, 540 pages, ISBN-10:0444518320, ISBN-13:978-0444518323 [in English].

George M. Zaslavsky, Hamiltonian Chaos and Fractional Dynamics, Oxford University Press, 2008 , 432 pages, ISBN10:0199535485, ISBN-13:978-0199535484 [in English].

Vladimir V. Uchaikin, Method of Fractional Derivatives, Artishok-Press, Ulyanovsk, 2008, 510 pages, ISBN:978-5-90419801-5. [in Russian].

Shantanu Das, Functional Fractional Calculus for System Identification and Controls, Springer, 2009, 260 pages, ISBN10:3642091784, ISBN-13:978-3642091780 [in English].

Timothy Margulies, Mathematics and Science Applications and Frontiers: with Fractional Calculus, Xlibris Corporation, 2008, 296 pages, ISBN-10:1425758517, ISBN-13:978-1425758516 [in English].

A.M. Mathai, Hans J. Haubold, Special Functions for Applied Scientists, Springer, 2008, 470 pages, ISBN-10:0387758933, ISBN-13:978-0387758930 [in English].

Dingyu Xue, YangQuan Chen, Derek P Atherton, Linear Feedback Control: Analysis and Design with MATLAB, Society for Industrial Mathematics, 2008, 370 pages, ISBN-10:0898716381, ISBN-13:978-0898716382. Chapter 8: Fractional Order Controller: An Introduction (pages 283-304) [in English].

Dingyu Xue, YangQuan Chen, Solving Applied Mathematical Problems with MATLAB, Chapman \& Hall/CRC Press, 2008, 448 pages, ISBN-10:1420082507, ISBN-13:978-1420082500. Sec. 10.6: Fractional Order Calculus [in English].

Vsevolod V. Vasil'ev, Lidiya A. Simak, Fractional Calculus and Approximation Methods in Modelling of Dynamic Systems, NAS (Nat. Acad. Sci.) of Ukraine, Academic Press, Kiev, 2008, 256 pages, ISBN:978-966-02-4384-2 [in Russian].

George A. Anastassiou, Fractional Differentiation Inequalities, Springer, 2009, 686 pages, ISBN-10:0387981276, ISBN13:978-0387981277 [in English].

V. Lakshmikantham, S. Leela, J. Vasundhara Devi, Theory of Fractional Dynamic Systems, Cambridge Scientific Publishers, Cambridge, 2009. 176 pages, ISBN:978-1-904868-64-4 [in English].

A.M. Mathai, Ram Kishore Saxena, Hans J. Haubold, The H-Function: Theory and Applications, Springer, 2009 , 270 pages, ISBN-10:144190915X, ISBN-13:978-1441909152 [in English].

Yu.A. Brychkov, Handbook of Special Functions. Derivatives, Integrals, Series and Other Formulas, Chapman and hall/CRC Press, Boca Raton FL, 2009, pages 780, ISBN:978-1-58488-956-4. 
Francesco Mainardi, Fractional Calculus and Waves in Linear Viscoelasticity: An Introduction to Mathematical Models, Imperial College Press, 2010, 300 pages, ISBN-10:1848163290, ISBN-13:978-1848163294 [in English].

Riccardo Caponetto, Giovanni Dongola, Luigi Fortuna, Ivo Petráš, Fractional Order Systems: Modeling and Control Applications, World Scientific Publishing Company, 2010, 200 pages, ISBN-10:9814304190, ISBN-13:978-9814304191 [in English].

Concepcion Alicia Monje, YangQuan Chen, Blas Manuel Vinagre, Dingyu Xue, Vicente Feliu, Fractional Order Systems and Controls: Fundamentals and Applications, Series: Advances in Industrial Control, Springer, to appear 2010 [in English].

Vasily E. Tarasov, Fractional Dynamics: Applications of Fractional Calculus to Dynamics of Particles, Fields and Media, Higher Education Press and Springer, ISBN:978-7-04-029473-6, ISBN:978-3-642-xxxxx-9, To appear in 2010 [in English].

Kai Diethelm: The Analysis of Fractional Differential Equations, Lecture Notes in Mathematics Series - Springer, To appear in 2010/2011 [in English].

Dumitru Baleanu, Kai Diethelm, Enrico Scalas, Juan J. Trujillo, Fractional Calculus: Models and Numerical Methods, World Scientific Publishing Company, To appear 2011 [in English].

Yu. F. Luchko, Operational Method in Fractional Calculus, Lecture Notes in Mathematics Series - Springer, To appear in 2011/12 [in English].

\section{Conferences}

\subsection{Conferences devoted to fractional calculus}

International Conference "Fractional Calculus and Its Applications", held at the University of New Haven, June/1974, Editor and Organizer: Bertram Ross.

International Conference (Workshop) "Fractional Calculus", held at Ross Priory - University of Strathclyde, Scotland, August/1984, Editors and Organizers: Adam C McBride, Gary F. Roach.

International Conference "Fractional Calculus and its Applications", Center of Nihon University, Tokyo, 29/May-1/June/ 1989, Organizer: Katsuyuki Nishimoto.

1st Intern. Workshop "Transform Methods \& Special Functions, Sofia'1994” (with Special session on FC), Sofia, August/ 1994, Organizers: P. Rusev, I. Dimovski, S.L. Kalla, V. Kiryakova, L. Boyadjiev.

2nd Intern. Workshop "Transform Methods \& Special Functions, Varna'1996” (with Special session and Round Table "Open Problems in FC"), August/1996, Organizers: P. Rusev, I. Dimovski, S.L. Kalla, V. Kiryakova, L. Boyadjiev.

Fractional Differential Systems: Models, Methods and Applications, European Society for Applied and Industrial Mathematics (ESAIM), Denis Matignon, Gérard Montseny (Editors), vol. 5, 3-4/December/1998, 204 pages, Electronic book, free download: http://www.esaim-proc.org [in French and English].

3rd Intern. Workshop "Transform Methods \& Special Functions, AUBG'1999” (with Special session on FC), Blagoevgrad, August/1999, Organizers: P. Rusev, I. Dimovski, S. L. Kalla, V. Kiryakova, L. Boyadjiev.

AMADE 1999 - The 1st International Conference "Analytic Methods of Analysis and Differential Equations", 14-18/September/1999, Minsk, Belarus, Organizer: Anatoly A. Kilbas et al.

AMADE 2001 - The 2nd International Conference "Analytic Methods of Analysis and Differential Equations", 15-19/February/2001, Minsk, Belarus, Organizer: Anatoly A. Kilbas et al.

1st FDTA - First Symposium on Fractional Derivatives and Their Applications, Organizing Committee: Om Agrawal, J.A. Tenreiro Machado, Jocelyn Sabatier, at the VIB'03 - ASME Int. 19th Biennial Conference on Mechanical Vibration and Noise, 2-6/September/2003, Chicago, Illinois, USA.

AMADE 2003 - The 3rd International Conference "Analytic Methods of Analysis and Differential Equations", 4-9/September/2003, Minsk, Belarus, Organizer: Anatoly A. Kilbas et al.

4th Intern. Workshop "Transform Methods \& Special Functions, Borovets'2003” (with Special session on FC), Borovets, September/2003, Organizers: P. Rusev, I. Dimovski, S.L. Kalla, S. Pilipovic, V. Kiryakova, L. Boyadjiev (in frames of 1st MASSEE Congress).

FDA'04 - First IFAC Workshop on Fractional Differentiation and its Applications, 19-21/July/2004, Bordeaux, France. National Organizing Committee: A. Oustaloup (Chairman), D. Camon (Co-chairman), H. Guéguen, P. Lanusse, R. Malti, P. Melchior, X. Moreau, L. Nivanen, J. Sabatier, J. Zaytoon. Chairman: S. Samko, Co-chairman: A. Oustaloup.

ENOC 2005 - Fifth EUROMECH Nonlinear Dynamics Conference, 7-12/August/2005, Eindhoven University of Technology, The Netherlands, Mini-Symposium: Fractional Derivatives and Their Applications, Chair/Organizers: J.A. Tenreiro Machado, Om P. Agrawal, Jocelyn Sabatier.

2nd FDTA - Second Symposium on Fractional Derivatives and Their Applications, Organizing Committee: Om P. Agrawal, J.A. Tenreiro Machado, Jocelyn Sabatier, at the IDETC/CIE 2005 ASME 2005 International Design Engineering Technical Conferences \& Computers and Information in Engineering Conference, 24-28/September/2005, Long Beach, California, USA.

AMADE 2006 - The 4th International conference "Analytic Methods of Analysis and Differential Equations", 13-19/September/2006, Minsk, Belarus, Organizer: Anatoly A. Kilbas et al. 
Fractional Derivatives for Mechanical Engineering: State-of-the-Art and Applications, 17/November/2006, Organization committee: J.-F. Deü, F. Dubois, A.C. Galucio Bourdet, D. Matignon, O. Thomas, Conservatoire National des Arts et Métiers, Paris, France.

FDA'06 - Second IFAC Workshop on Fractional Differentiation and its Applications, 19-21/July/2006, Porto, Portugal. Organizing Committee: J. A. Tenreiro Machado, Manuel F. Silva, Lino Figueiredo, Ramiro Barbosa, Alexandra Galhano. Chair: Stefan Samko, Co-Chair: Blas M.Vinagre.

The 5th International Conference on Engineering Computational Technology, Las Palmas de Gran Canaria, Spain, 12-15/ September/2006, Sessions: Fractional Differential Equations: Theory and Applications, Organizer: J.J. Trujillo Jacinto del Castillo.

CFD'07 - 1st Classic and Fractional Dynamics on Continuous and Discontinuous Vector Fields, Organizing Committee: Albert Luo, J.A. Tenreiro Machado, at the MSNDC07-6th International Conference on Multibody Systems, Nonlinear Dynamics, and Control, IDETC - 2007 ASME International Design Engineering Technical Conferences, 4-7/September/2007, Las Vegas, Nevada, USA.

3rd FDTA - Third Symposium on Fractional Derivatives and Their Applications, Organizing Committee: Om Agrawal, Jocelyn Sabatier, Dumitru Baleanu, Blas Vinagre, YangQuan Chen, at the IDETC - 2007 ASME International Design Engineering Technical Conferences, 4-7/September/2007, Las Vegas, Nevada, USA.

SAFC07 - Symposium on Applied Fractional Calculus, 15-17/October/2007, Badajoz, Spain. Organizing Committee: Blas M. Vinagre, University of Extremadura (Chair), Luis Vázquez, Juan J. Trujillo, Santos Bravo, Concepción A. Monje, Inés Tejado.

Mini-Symposium Fractional Derivatives and Their Applications, Chair/Organizers: J.A. Tenreiro Machado, Alexander Belyaev, Om Agrawal, at the ENOC 2008-6th EUROMECH Conference, 30/June - 4/July/2008, Saint Petersburg, Russia.

Fractional Flows Workshop, Organizer: Niels Jacob, 18-19/September/2008, Univ. of Warwick, Coventry, UK.

FDA'08 - Third IFAC Workshop on Fractional Differentiation and its Applications, Ankara, Turkey, 5-7/November/ 2008. Organizing Committee: Dumitru Baleanu (Chair), Yahya Kemal Baykal, Ozlem Defterli, Erdal Dinc, Lino Figueiredo, Serdar Ethem Hamamci, Haldun Ozaktas, Manuel Silva. Chair: J.A. Tenreiro Machado, Co-Chairs: Alain Oustaloup, Wen Chen.

CFD'09 - 2nd Classic and Fractional Dynamics on Continuous and Discontinuous Vector Fields, Organizers: Albert Luo, J.A. Tenreiro Machado, at the IDETC-ASME 2009 International Design Engineering Technical Conferences \& CIE-Computers and Information in Engineering Conference, San Diego, California, USA, 30/August - 2/September/2009.

4th FDTA - Fractional Derivatives and Their Applications, Organizers: Om Prakash Agrawal, Dumitru Baleanu, YangQuan Chen, Jocelyn Sabatier, Blas M. Vinagre, at the IDETC-ASME 2009 International Design Engineering Technical Conferences \& CIE - Computers and Information in Engineering Conference, San Diego, California, USA, 30/August - 2/September/2009.

AMADE 2009 - The 5th International conference "Analytic Methods of Analysis and Differential Equations", 14-19/September/2009, Minsk, Belarus, Organizers: I.V. Gaishun, M.V. Dubatovskaya, A.A. Kilbas, S.V. Rogosin, M.A. Zhuravkov.

FSS'09 - Symposium on Fractional Signals and Systems, Lisbon, Portugal, 4-6/November/2009. National Organizer: M.D. Ortigueira, Chair: Manuel Ortigueira, Co-Chairs: Blas Vinagre, J. Tenreiro Machado, Juan J. Trujillo.

Mini-Symposium: Fractional Dynamics and Control, Organizers: Changpin Li, YangQuan Chen, Wen Chen, at the ICDVC2010 - The Third International Conference on Dynamics, Vibration and Control, 12-14/May/2010, Hangzhou, China.

Academic Day of Fractional Dynamics and Control, 16-18/May/2010, Shanghai University, Shanghai, China, Chairman: Prof. Changpin Li, Shanghai University, Co-Chairman: Prof. Wen Chen, Hohai University.

The First Symposium on Fractional Order Dynamic Systems and Controls, Chair: Yan Li, at the 2010 IEEE/ASME International Conference on Mechatronic and Embedded Systems and Applications, 15-17/July/2010, Qingdao, ShanDong, China (Sponsored by the IEEE Intelligent Transportation Systems Society, Technical-sponsored by American Society of Mechanical Engineers).

FDA'10 - 4th IFAC Workshop on Fractional Differentiation and Its Applications, University of Extremadura, Badajoz, Spain, 18-20/October/2010. Organising Committee: Blas M. Vinagre Jara (Chair), Vicente Feliu Batlle, Santos Bravo Yuste, Inés Tejado Balsera, Antonio J. Calderón Godoy, Igor Podlubny, Ivo Petras, Tomas Skovranek, Dagmar Bednarova, Andrea Mojzisova. Chair: YangQuan Chen.

FSS'11 - Symposium on Fractional Signals and Systems, Coimbra, Portugal, 4-7/November/2011. Organizing Committee: Filomena Canova, Jorge Barbosa, Nuno Ferreira, Deolinda Simões, Chair: J. Tenreiro Machado, Co-Chair: M. D. Ortigueira, Blas Vinagre, Juan J. Trujillo.

Mini-Symposium: Fractional Derivatives, Chair/Organizers: J.A. Tenreiro Machado, Alexander Belyaev, Om P. Agrawal, at the ENOC 2011-7th European Nonlinear Dynamics Conference, Rome, Italy, 24-29/July/2011.

\subsection{Special sessions in conferences}

ECC 2001 - European Control Conference, 4-7/September/2001, Porto, Portugal. Special sessions: Fractional Order Systems - Part 1, Fractional Order Systems - Part 2, Organizer: J.A. Tenreiro Machado.

CIFA'2002 - 2ème IEEE Conférence Internationale Francophone d'Automatique, Nantes, France, 8-10/July/2002. Invited session: Application de la dérivation fractionnaire en modélisation, identification et commande - Systèmes fractionnaires, Organizers: Jocelyn Sabatier, Patrick Lanusse. 
Controlo'2002 - 5th Portuguese Conference on Automatic Control, 5-7/September/2002, Aveiro, Portugal. Special sessions: Fractional Order Systems 1, Fractional Order Systems 2, Organizer: J.A. Tenreiro Machado.

ICCC'2003 - International Carpathian Control Conference, Hight Tatras, Slovakia, Special Session 8: Fractional derivatives in modeling and control, May/2003, President of Int. Program Committee: Igor Podlubny.

ICAR 2003 - The 11th International Conference on Advanced Robotics. 30/June - 3/July/2003, Coimbra, Portugal, Special Sessions: Fractional Derivatives in Mechatronics and Robotics 1, Fractional Derivatives in Mechatronics and Robotics 2, Organizers: Pierre Melchior, Patrick Lanusse, Jocelyn Sabatier.

ICCC 2004 - IEEE International Conference on Computational Cybernetics, Vienna University of Technology, Austria, 30/ August - 1/September/2004. Sessions: "Fractional Order Systems 1", "Fractional Order Systems 2". Organizer: J.A. Tenreiro Machado.

ICCC 2006 - IEEE International Conference on Computational Cybernetics, 20-22/August/2006, Tallinn, Estonia. Special session: Fractional calculus, Organizer: J.A. Tenreiro Machado.

IECON 2006 - 32th IEEE Industrial Electronics Conference, Paris, France, 6-10/November/2006. Special Sessions: Fractional Differentiation and their Applications - 1, Fractional Differentiation and their Applications - 2, Organizers: P. Melchior and J. Sabatier.

ICINCO 2007 - 4th International Conference on Informatics in Control, Automation and Robotics, 9-12/May/2007, Angers, France, Special Session: Fractional Order Systems, Organizer: Samir Ladaci.

NSC'08 - 2nd Conference on Nonlinear Science and Complexity, 28-31/July/2008, Porto, Portugal, Symposium: Fractional Calculus Applications, Organizers: Ramiro Barbosa, Manuel Silva.

NTST 08 - Int. Workshop on New Trends in Science and Technology, Ankara, Turkey, 3-4/November/2008, Editors: Ziya Burhanettin Güvenç, Cem Özdoğan, Dumitru Baleanu.

ICCES 09 - The 16th International Conference on Computational and Experimental Engineering \& Sciences, Thailand, 813/April/2009, Session Title: Numerical Methods for Governing Equations Including Fractional Derivatives, Organizers: Wen Chen.

Academic Conference of China Society of Mechanics, Zhengzhou, China, 24-26/August/2009, Session Title: Symposium of Fractional Dynamic System and its Applications, Organizers: Keqin Zhu, Wen Chen, Changpin Li.

ICDVC 2010 - The Third International Conference on Dynamics, Vibration and Control, Hangzhou, China, 12-14/May/ 2010. Session Title: Fractional Dynamics and Control, Organizers: Changpin Li, YangQuan Chen, Wen Chen.

SOFA 2010 - Systèmes d'Ordre Fractionnaire et leurs Applications, University of Skikda, Algeria, 18-19/May/2010, Organizer: Samir Ladaci.

ISIE 2010 - IEEE Int. Symposium on Indstrial Electronics, Bari, Italy, 4-7/July/2010, Special Session: Theoretical Advances and Industrial Applications of Fractional Calculus, Organizer: Donato Cafagna.

NSC'10 - 3rd Conference on Nonlinear Science and Complexity, 28-31/July/2010, Ankara, Turkey, Symposium: Fractional Calculus Applications, Organizer: Dumitru Baleanu, Co-Organizer: Diego del-Castillo-Negrete.

MESA'10 - 2010 IEEE/ASME International Conference on Mechatronic and Embedded Systems and Applications, 15-17/ July/2010, Qingdao, ShanDong, China. Symposium: Fractional Dynamics and Controls, Chair: Yan Li.

\subsection{Courses, tutorials and plenaries}

\subsubsection{Courses}

P. Lanusse, A. Oustaloup, B. Mathieu, Présentation du module "Commande" du logiciel CRONE: application à la commande du bras flexible du LAG, Ecole de printemps "Commande robuste", Douz, Tunisie, 21-25/March/1994.

R. Gorenflo, Abel Integral Equations with Special Emphasis on Applications, Lectures in Math. Sciences - The University of Tokyo, June-August/1995; Publ. as L.M.S. - Univ. of Toky, \#13, 1996, 56 pages, ISSN:0919-8180.

P. Lanusse, A. Oustaloup, Mise en oeuvre de la commande CRONE à l'aide du module "Commande" du logiciel CRONE, Ecole d'Automne sur la commande CRONE, Hammamet, Tunisie, 3-6/October/1994.

Tutorial Workshop: Fractional Calculus Applications in Automatic Control and Robotics, CDC02 - 41st IEEE Conference on Decision and Control, 10-13/Dec/2002, Las Vegas, Nevada, USA. Organizers: Blas M. Vinagre, YangQuan Chen. Colaboration: Lokenath Debnath, Pierre Melchior, Patrick Lanusse, J. Tenreiro Machado.

Course: Fractional order models and fractional differential equations in science and engineering. Instructor: Igor Podlubny. Utah State University, USA, 2007. Reference: ECE 5930 003/ECE 6930003.

Course: Applied Fractional Calculus in Science and Engineering. Instructors: Changpin Li, Yan Li, Dingyu Xue, YangQuan Chen. Utah State University, USA, June 08 - Jul 31/2009. Reference: ECE6930.

Tutorial Session: Applied Fractional Calculus in Controls, 2009 American Control Conference, 10-12/June/2009, St. Louis, Missouri, USA. Organizer: YangQuan Chen.

Course: Fractional Calculus. Instructor: Francesco Mainardi. 2010 SERC School at CMS Pala Campus [8th SERC School at CMS], Centre of Mathematical Sciences, April-May/2010, Pala, Kerala, India.

\subsubsection{Tutorials}

P. Melchior, P. Lanusse, F. Dancla, O. Cois, A. Oustaloup, Le logiciel CRONE, Colloque sur l'Enseignement des Technologies et des Sciences de l'Information et des Systèmes en EEA, CETSIS-EEA'99, Montpellier, 4-5/November/1999. 
A. Oustaloup, F. Dancla, P. Melchior, P. Lanusse, O. Cois, Développement d'une nouvelle bo^ıte à outils Matlab: le logiciel CRONE - Journée du Club Utilisateurs Matlab, JML'2000, Laboratoire de Mathématiques, Université de Reims ChampagneArdenne, IFP, SSG, Reims, 5/May/2000.

P. Melchior, P. Lanusse, F. Dancla, O. Cois, "CRONE Toolbox": une bo^ıte à outils Matlab pour les systèmes fractionnaires, Colloque sur l'Enseignement des Technologies et des Sciences de l'Information et des Systèmes en EEA, CETSIS-EEA'2001 Clermont-Ferrand, France, 29-30/October/2001.

O. Cois, P. Melchior, P. Lanusse, F. Dancla, A. Oustaloup, Fractional systems toolbox for Matlab: "System Identification by Fractional Model" module, Tutorial Workshop on "Fractional Calculus Applications in Automatic Control and Robotics", 41st IEEE Conference on Decision and Control (CDC'02), Las Vegas, Nevada, USA, 9-13/December/2002.

P. Lanusse, J. Sabatier, X. Moreau, A. Oustaloup, Fractional systems toolbox for Matlab: "CRONE Control-System Design" module, Tutorial Workshop on "Fractional Calculus Applications in Automatic Control and Robotics", 41st IEEE Conference on Decision and Control (CDC'02), Las Vegas, Nevada, USA, 9-13/December/2002.

P. Melchior, P. Lanusse, O. Cois, F. Dancla, A. Oustaloup, Crone Toolbox for Matlab: Fractional Systems Toolbox, Tutorial Workshop on "Fractional Calculus Applications in Automatic Control and Robotics", 41st IEEE Conference on Decision and Control (CDC'02), Las Vegas, Nevada, USA, 9-13/Dec/2002.

P. Melchior, B. Orsoni, A. Oustaloup, Fractional systems toolbox for Matlab: "Fractional Path Planning and Path Tracking Design" module, Tutorial Workshop on "Fractional Calculus Applications in Automatic Control and Robotics", 41st IEEE Conference on Decision and Control (CDC'02), Las Vegas, Nevada, USA, 9-13/Dec/2002.

A. Oustaloup, P. Lanusse, B. Mathieu, Approche fréquentielle et non entière de la robustesse: la commande CRONE, Ecole d'Eté Européenne d'Automatique de Grenoble (CNRS-DRED) "Robustesse: analyse et synthèse de commandes robustes", ENSEIG, Grenoble, 6-10/September/1993.

\subsubsection{Plenary lectures}

Transform Methods \& Special Functions'94, Sofia, Bulgaria, 12-17/August/1994. Plenary Lecture: Virginia Kiryakova, Generalized fractional calculus, special functions and integral transforms.

TMSF, Varna '96 - 2nd International Workshop “Transform Methods \& Special Functions”, Varna, 23-30/August/1996, Convenor of Round Table Discussion on Open Problems in FC: Virginia Kiryakova, and discussions published in the Proc., as: “A long standing conjecture failed?" (pp. 584-593, see at Zbl 0951.26004).

ICSC'1999 - International Conf. on Scientific Computations'1999, Lebanese American University - Beirut, 15-17/March/ 1999, Plenary lecture: Virginia Kiryakova, Representations and computational procedures for special functions via generalized fractional calculus.

ICONNE'2000 - International Conference on Nonlinear Dynamics, Chaos, Control and Their Applications in Engineering Sciences, 31/July-4/August/2000, Campos do Jordão, SãoPaulo, Brazil. Plenarylecture:J.A. TenreiroMachado, System Modeling and Control Through Fractional Order Algorithms.

INES'2002 - 6th IEEE International Conference on Intelligent Engineering Systems 2002, 26-29/May/2002, Opatija, Croatia. Plenary lecture: J.A. Tenreiro Machado, Application of Fractional Calculus in the Control of Mechanical Systems.

FDA 04 - 1st IFAC Workshop on Fractional Differentiation and its Applications, 19-21/July/2004, Bordeaux, France.

Plenary Lectures:

- Alain Le Mehaute, Raoul R. Nigmatullin, New Engineering and design tools based on fractional differentiation.

- Michael Unser, Fractional splines, wavelet bases and applications.

- Rudolf Gorenflo, Francesco Mainardi, Power laws, random walks, and fractional diffusion processes as well-scaled refinement.

FDA 06 - 2nd IFAC Workshop on Fractional Differentiation and its Applications, 19-21/July/2006, Porto, Portugal. Plenary Lectures:

- Francesco Mainardi, Fractional relaxation and fractional diffusion of distributed order.

- Stefan G. Samko, Periodization of Fractional Integrals.

- Katsuyuki Nishimoto, N-Fractional Calculus and Its Applications.

- Alain A. Oustaloup, The CRONE approach: Theoretical Developments and Major Applications.

- YangQuan Chen, Ubiquitous Fractional Order Controls?

ICCC 2006 - IEEE 2006 International Conference on Computational Cybernetics, 20-22/August/2006, Tallinn, Estonia. Plenary lecture: J.A. Tenreiro Machado, Fractional Calculus and Dynamical Systems.

IX Triennal Internat. SAUM Conf. on Systems, Automatic Control and Measurements, November/2007, Plenary lecture: Virginia Kiryakova, The Fractional calculus' functions: Mittag-Leffler functions, some applications in control theory, generalizations and open problems.

FDA 08 - 3rd IFAC Workshop on Fractional Differentiation and its Applications, 05-07/November/2008, Ankara, Turkey.

Plenary Lectures: 
- R.R. Nigmatullin, Dielectric Relaxation Based on the Fractional Kinetics: Theory and its Experimental Confirmation.

- Y.Q. Chen, Fractional Order Signal Processing: Techniques, Applications and Urgency.

- D. Baleanu, Fractional Variational Principles and their Applications.

- B. Vinagre, Looking at Fractional Order Control in Perspective.

- E. Scalas, On the Application of Fractional Calculus in Finance and Economics.

- R. Magin, Fractional Calculus in Bioengineering: a Tool to Model Complex Dynamics in Multiscale Structures.

- J.J. Trujillo, On Best Fractional Derivative to be Applied in Fractional Modelling: The Fractional Fourier Transform.

- J. Sabatier, On Stability of Fractional Order Systems.

MIC 2008 - The 27th IASTED International Conference on Modelling, Identification, and Control, 11-13/February/ 2008, Innsbruck, Austria. Plenary lecture: J.A. Tenreiro Machado, Fractional Calculus: Application in Modeling and Control.

ENOC 2008 - 6th EUROMECH Conference, 30/June - 4/July/2008, Saint Petersburg, Russia. Plenary lecture: Om P. Agrawal and J.A. Tenreiro Machado, Fractional Derivatives and Their Applications,

CLAWAR'2008-11th International Conference on Climbing and Walking Robots and the Support Technologies for Mobile Machines, 8-10/September/2008, Coimbra, Portugal. Plenary Lecture: J.A. Tenreiro Machado, Fractional Calculus: Application in Control and Robotics.

ICCC08 - IEEE 6th International Conference on Computational Cybernetics, 27-29/November/2008, Stara Lesná, Slovakia. Plenary Lecture: J.A. Tenreiro Machado, Application of Fractional Calculus in Engineering Sciences.

Robocontrol'08, 4-5/December/2008, Bauru, Brazil. Plenary Lecture: J.A. Tenreiro Machado, Fractional Calculus: Application in Control and Robotics.

DSTA 2009 - 10th Conference on Dynamical Systems - Theory and Applications, 7-10/Dec/2009, Łódz' , Poland. Plenary Lecture: J.A. Tenreiro Machado, Fractional Dynamics representation in the pseudo phase plane.

ICMS-AUS'2010 - 1st Intern. Conf. Mathematics and Statistics, American University of Sharjah'2010, March/2010, UAE, Plenary Lecture: Virginia Kiryakova, Special functions of fractional calculus - Survey, list and new results.

\subsection{Thematic events}

Journées d'Etude de l'Action Thématique "Les systèmes à dérivées non entières: théorie et applications" - Club EEA, SEE, GdR SDSE et Automatique du CNRS. Organizers: A. Oustaloup, J. Sabatier, X. Moreau.

- LAP-ENSEIRB, Bordeaux, France, 10/June/1999.

- LAP-ENSEIRB, Bordeaux, France, 3-4/October/2001.

- LAII-ESIP, Poitiers, France, 28-29/March/2002.

- IRCCyN, Nantes, France, 24-25/October/2002.

- LAP-ENSEIRB, Bordeaux, France, 27-28/March/2003.

- LAP-ENSEIRB, Bordeaux, France, 16-17/October/2003.

- ENIT, Tarbes, France, 25-26/March/2004.

- ISMANS, Le Mans, France, 10-11/February/2005.

- LAP-ENSEIRB, Bordeaux, France, 24-25/November/2005.

- CNAM, Paris, France, 6-7/November/2006.

- ENSIEG, Grenoble, France, 11-12/June/2007.

- ENSEIRB, Bordeaux, France,27-28/November/2007.

Fractional Order Calculus Day at Utah State University, USA, 19/April/2005, 3/September/2007, 24/April/2009.

\section{Journals}

Fractional Calculus \& Applied Analysis (Fract. Calc. Appl. Anal.), ISSN:1311-0454

Institute of Mathematics and Informatics, Bulgarian Academy of Sciences.

Managing Editor: Virginia Kiryakova, Website: http://www.math.bas.b»t fcaa, http://www.diogenes.bg/fcaa.

Starting year: 1998 (vol. 1); currently: vol. 13 (2010).

Journal of Fractional Calculus, ISSN:0918-5402, Descartes Press Co.

Editor-in-Chief: Katsuyuki Nishimoto, Starting year: 1992.

Fractional Dynamic Systems.

Ele-Math's, Editors-in-chief: Josip Pečarić, Yong Zhou, Website: http://fds.ele-math.com/.

Starting year: 2010 . 


\section{FC algorithms/packages}

\subsection{Matlab central file exchange}

Date: 03/June/2003. File: A New IIR-type Digital Fractional Order Differentiator A New IIR-type Digital Fractional Order Differentiator. Author: YangQuan Chen. Tags: Fractional order calculus, filter design, filter, filter analysis, iir, digital differentiator.

Date: 03/June/2003s. File: Digital Fractional Order Differentiator/Integrator - IIR Type General IIR Digital Differentiator/ Integrator. Author: Ivo Petras. Tags: Filter design, filter analysis, fractional calculus, digital integrator.

Date: 03/July/2003. File: Digital Fractional Order Differentiator/integrator - FIR Type. General FIR Digital Differentiator/ Integrator. Author: Ivo Petras. Tags: Filter design, filter analysis, fractional calculus, digital integrator, digital differentiator.

Date: 22/October/2003. File: Processed Imagery of the Great Red Spot, Jupiter 3D Fractional Order Sunshaded Image of the Great Red Spot, Jupiter. Author: Gordon Cooper. Tags: Fractional order, gallery, sunshaded, red spot, image, 3d.

Date: 22/October/2003. File: 3D Fractional Order Sunshaded Image Overlain on Original Data in 3D. Author: Gordon Cooper. Tags: Gallery, color, 3d, geophysics, aeromagnetic, sunshading.

Date: 10/March/2008. File: Ninteger Toolbox to Help Developing Fractional Order Controllers and Assess their Performance. Author: Duarte Valério. Tags: Fractional control, fractional calculus, fractional plants, fractional.

Date: 31/March/2008 (Updated 30/June/2008). File: Mittag-Leffler pseudo-random number generator. Author: Guido Germano. Tags: Mittagleffler distribution, probability, random number generator, statistics.

Date: 16/July/2008. File: Mittag-Leffler function, M-file, cmex DLL, and S-function Mittag-Leffler Function, M-file, cmex DLL, and S-function. Author: Shayok Mukhopadhyay. Tags: M-file, fractional calculus, cmex, mittag leffler.

Date: 28/July/2008. File: Generalized Mittag-Leffler Function Computes Generalized Mittag-Leffler Function. Author:

YangQuan Chen. Tags: Special function, mittagleffer function, fractional calculus, general.

Date: 08/September/2008. File: Impulse Response Invariant Discretization of Fractional Order Integrators/Differentiators Compute a Discrete-time Finite Dimensional (z) Transfer Function to Approximate $s^{r}, r$ is real number. Author: YangQuan Chen. Tags: Fractional order integrator, filter design, filter analysis, fractional calculus, fractional.

Date: 08/Sep/2008. File: Step Response Invariant Discretization of Fractional Order Integrators/Differentiators Compute a Discrete-time Finite Dimensional (z) Transfer Function to Approximate $s^{r}, r=$ real number. Author: YangQuan Chen. Tags: Fractional order integrator, filter design, filter analysis, fractional calculus, fractional.

Date: 08/September/2008. File: Impulse Response Invariant Discretization of Fractional Order Low-pass Filters Discretize t $k=$ ds $\mathbf{p}$ wifth " $r$ " a real number. Author: YangQuan Chen. Tags: Pass, filter design, fraction, filter, filter analysis, fractional calculus.

Date: 17/September/2008. File: Generalized Mittag-Leffler function in four parameters. Author: YangQuan Chen. Tags: Math, generalized mittagleffler function.

Date: 25/March/2009. File: Mittag-Leffler Function Calculates the Mittag-Leffler Function with Desired Accuracy. Author: Igor Podlubny. Tags: Special functions, fractional calculus, mittagleffler function.

Date: 18/May/2009. File: Matrix Approach to Discretization of ODEs and PDEs of Arbitrary Real Order Functions Illustrating Matrix Approach to Discretization of ODEs/PDEs with Fractional Derivatives. Author: Igor Podlubny. Tags: Differential, discretization, mathematics, fractional differential, fractional derivative, fractional diffusion equation.

Date: 30/November/2009. File: Variable Order Derivatives Functions for Implementing Fractional or Complex Order Derivatives, When the Order Changes with Time. Author: Duarte Valério. Tags: Fractional derivatives, fractional control, fractional calculus, variableorder derivatives.

Date: 14/January/2010. File: Impulse Response Invariant Discretization of Distributed Order Integrator Compute a Discrete-time Transfer Function to Approximate a Distributed Order Integrator. Author: Hu Sheng. Tags: Fractional order filter, fractional order calculus, distributed order integrator.

Date: 19/January/2010. File: Predictor-Corrector Method for Variable-order, Random-order Fractional Relaxation Equation, Predictor-Corrector Method for Variable-order and Random-order Fractional Equations. Author: Hongguang Sun. Tags: Self_rating, fractional relaxat.

Date: 21/January/2010. File: Impulse Response Invariant Discretization of Fractional Second Order Filter. The Function Compute a Discrete-time Transfer Function to Fractional Second Order Low-pass Filter. Author: Hu Sheng. Tags: Fractional second order filter, fractional calculus, fractional system.

Date: 06/March/2010. File: Impulse Response Invariant Discretization of Distributed Order Low-pass Filter Compute a Discrete-time Transfer Function to Approximate a Distributed Order Low-pass Filter. Author: Hu Sheng. Tags: Fractional calculus, distributed order lowpass filter, fractional signal processing.

CRONE Toolbox for Matlab: http://www.ims-bordeaux.fr/IMS//pages/pageAccueilPerso.php?email=alain. oustaloup.

\subsection{Resources from Wolfram Mathworld}

With code:

Weisstein, Eric W. "Fractional Derivative." From MathWorld - A Wolfram Web Resource. 14/April/2004. http://mathworld.wolfram.com/FractionalDerivative.html. 
Weisstein, Eric W. "Fractional Integral." From MathWorld - A Wolfram Web Resource. 14/April/2004. http://mathworld.wolfram.com/FractionalIntegral.html.

Weisstein, Eric W. "Mittag-Leffler Function.” From MathWorld - A Wolfram Web Resource. 21/September/2008. http:// mathworld.wolfram.com/Mittag-LefflerFunction.html.

Weisstein, Eric W. "Wright Function.” From MathWorld - A Wolfram Web Resource. 3/January/2009. http://mathworld.wolfram.com/WrightFunction.html.

Coded by Weisstein, 25/September/2003. Eric W. Ozaktas, H.M., Zalevsky, Z., and Kutay, M.A. The Fractional Fourier Transform, with Applications in Optics and Signal Processing. New York, Wiley, 2000. http://www.ee.bilkent.edu.trr-haldun/ wileybook.html.

Entries without code:

Weisstein, Eric W. "Fractional Calculus.” From MathWorld - A Wolfram Web Resource. http://mathworld.wolfram.com/ FractionalCalculus.html.

Weisstein, Eric W. "Riemann-Liouville Operator." From MathWorld - A Wolfram Web Resource. http://mathworld.wolfram.com/Riemann-LiouvilleOperator.html.

Weisstein, Eric W. "Fractional Differential Equation." From MathWorld - A Wolfram Web Resource. http://mathworld.wolfram.com/FractionalDifferentialEquation.html.

Weisstein, Eric W. "Fractional Differential Equation." From MathWorld - A Wolfram Web Resource. http://mathworld.wolfram.com/FractionalDifferentialEquation.html.

Packages:

Gerd Baumann, package Fractional Calculus. Presented at the International Mathematica Symposium IMC99. Bauman G, Knocking on Leibniz Door, Journal Mathematica in Education and Research, Year 1999, vol. 8, No. 3-4, pp. 58-65. http:// library.wolfram.com/infocenter/Conferences/6139.

Demonstrations: Wolfram demonstration project

"Fractional Derivative of a Power" from The Wolfram Demonstrations Project. Contributed by: Jorge Gamaliel Frade Chávez. http://demonstrations.wolfram.com/FractionalDerivativeOfAPower/.

"Fractional Derivative of Sine" from The Wolfram Demonstrations Project. Contributed by: Jorge Gamaliel Frade Chávez. http://demonstrations.wolfram.com/FractionalDerivativeOfSine/.

"An Ordinary Fractional Differential Equation” from The Wolfram Demonstrations Project. Contributed by: Jorge Gamaliel Frade Chávez. http://demonstrations.wolfram.com/AnOrdinaryFractionalDifferentialEquation/.

"Fractional Fourier Transform" from The Wolfram Demonstrations Project. Contributed by: Enrique Zeleny. http://demonstrations.wolfram.com/FractionalFourierTransform/.

"Option Prices under the Fractional Black-Scholes Model” from The Wolfram Demonstrations Project. Contributed by: Andrzej Kozlowski. http://demonstrations.wolfram.com/OptionPricesUnderTheFractionalBlackScholesModel/.

"One-Dimensional Fractional Brownian Motion" from The Wolfram Demonstrations Project. Contributed by: Roman E. Maeder. http://demonstrations.wolfram.com/OneDimensionalFractionalBrownianMotion/.

"Probabilistic Interpretation of a Fractional Derivative". Contributed by: L.A. Mendes Afonso and J.A. Tenreiro Machado. http://demonstrations.wolfram.com/ProbabilisticInterpretationOfAFractionalDerivative/.

\subsection{Other websites and packages}

Kai Diethelm:

- The fractional Adams method (Fortran 77 version).

- The fractional backward differentiation formula (BDF) (Fortran 77 version).

- Lubich's fractional backward differentiation formulas (Matlab version).

http://www-public.tu-bs.de:8080/ reliethelm/software/software.html.

Duarte Valério, http://web.ist.utl.pt/duarte.valerio/ninteger/ninteger.htm.

Igor Podlubny, http://people.tuke.sk/igor.podlubny/fc.html.

YangQuan Chen, http://mechatronics.ece.usu.edu/foc/.

FraCalMo, http://www.fracalmo.org/.

Equipe CRONE, http://www.ims-bordeaux.fr/IMS//pages/accueilEquipe.php?guidPage=les_equipes.

Power Law \& Fractional Dynamics: http://www.ismm.ac.cn/ismmlink/PLFD/index.html.

\subsection{Some papers on computational/numerical procedures for special functions of FC}

R. Gorenflo, J. Loutchko, Yu. Luchko, Computation of the Mittag-Leffler function $E_{a l p h a ; ~}$ and its derivatives, Fract. Calc. Appl. Anal. 5 (2002), 491-518. 
K. Diethelm, N. Ford, A. Freed, Yu. Luchko, Algorithms for the fractional calculus: a selection of numerical methods, Comput. Methods Appl. Mech. Eng. 194 (2005), 743-773.

R. Hilfer, H.J. Seybold, Computation of the generalized Mittag-Leffler function and its inverse in the complex plane, Integr. Transform. Spec. Funct. 17 (2006), 637-652.

Yu. Luchko, Algorithms for evaluation of the Wright function for the real arguments' values, Fract. Calc. Appl. Anal. 11 (2008), 57-75.

D. Fulger, E. Scalas, G. Germano, Monte Carlo simulation of uncoupled continuous-time random walks yielding a stochastic solution of the space-time fractional diffusion equation, Phys. Rev. E 77 (2008), 021122.

6. Math keywords and entries in the new MSC2010 (Mathematics Subject Classification 2010), related to FC

26A33 - Fractional derivatives and integrals.

05C72 - Fractional graph theory, fuzzy graph theory.

33E12 - Mittag-Leffler functions and generalizations.

34A08 - Fractional ordinary differential equations.

34K37 - Functional-differential equations with fractional derivatives.

35R11 - Fractional partial differential equations.

60G22 - Fractional stochastic processes, including fractional Brownian motion.

\section{Patents}

Logiciel CRONE (Logiciel d'aide à la synhèse d'une commande CRONE), A.P.P. No. 93-30-006-00, 28/July/1993.

Module d'Identification du Logiciel CRONE, A.P.P. No. 94-11-015-00, 16/March/1994.

YangQuan Chen, Tuning Methods for Fractional Order Controllers, United States Patent 7,599,752, patent awarded on 6/ October/2009, filed on 17/May/2005.

A. Oustaloup, Y. Deval, D. Belot, P. Melchior, J.-B. Begueret, F. Badets, V. Lagareste, Frequency synthesizer, e.g. for radio transceiver, has loop filter of fractional order to control oscillator based on measured phase difference between its divided frequency and that of reference frequency oscillator, 15/December/2006.

G. Gregoire, F. Ragot, J. Sabatier, A. Oustaloup, R. Malti, Système d'estimation de l'état de charge de moyens de stockage d'énergie électrique de véhicule et procédé de calibrage, 28/April/2006.

F. Ragot, G. Gregoire, J. Sabatier, A. Oustaloup, R. Malti, Système de détermination de l'état de charge de moyens de stockage d'énergie électrique de véhicule, 28/April/2006.

F. Ragot, G. Gregoire, J. Sabatier, A. Oustaloup, R. Malti, System for determining the state of charge of electricity storage units of vehicles, 3/May/2006.

A. Oustaloup, Y. Deval, D. Belot, P. Melchior, J.-B. Begueret, F. Badets, V. Lagareste, Synthétiseur de frequence à PLL: PLL avec filtre d'ordre non entier, 31/March/2006. Extension USA, 29/June/2006.

O. Cois, P. Lanusse, A. Oustaloup, A. Wagner, R. Buehrle, Verfahren zum betreiben einer brennkraftmaschine (Electronic oscillation compensator for electronic air system valves of internal combustion engines), 12/April/2007.

O. Cois, P. Melchior, P. Lanusse, A. Poty, A. Oustaloup, R. Buehrle, Method for regulating an actual value of a variable which characterizes a position of an actuator, computer program product, computer program and recording medium, 2/August/ 2007. Extension EU, 15/October/2008. Extension USA.

F. Ragot, I. Bouygues, G. Gregoire, A. Oustaloup, J. Sabatier, Procédé et système d'estimation de l'état de charge de moyens de stockage d'énergie électrique, 2/February/2007.

R. Buehrle, O. Cois, P. Lanusse, A. Oustaloup, A. Wagner, Method for operating an internal combustion engine, 27/May/ 2008.

\section{Acknowledgments}

The authors thank for the suggestions of Dumitru Baleanu, Enrico Scalas, Hongguang Sun, Hu Sheng, Juan J. Trujillo, Kai Diethelm, Pierre Melchior, Raoul Nigmatullin, Rudolf Gorenflo, Stefan Samko, YangQuan Chen, Yury Luchko, Wen Chen.

The co-author J. Tenreiro Machado would like to acknowledge the support of GECAD - Grupo de Investigação em Engenharia do Conhecimento e Apoio à Decisão.

The co-author V. Kiryakova would like to acknowledge the partial support under Project D ID 02/25/2009 "Integral Transform Methods, Special Functions and Applications", by National Science Fund - Ministry of Education, Youth and Science, Bulgaria. 